\title{
Expression of ADAMTS-8, a secreted protease with antiangiogenic properties, is downregulated in brain tumours
}

\author{
JR Dunn*,', JE Reed', DG du Plessis², EJ Shaw', P Reeves', AL Gee', P Warnke² and C Walker' \\ 'JK Douglas Cancer Research Laboratories, Clatterbridge Hospital, Bebington, Wirral CH64 3JY, UK; ' ${ }^{2}$ Department of Neurological Science, University of \\ Liverpool, Lower Lane, Fazakerley, Liverpool, L9 7LJ, UK
}

\begin{abstract}
Angiogenesis and extracellular matrix degradation are key events in tumour progression, and factors regulating stromal-epithelial interactions and matrix composition are potential targets for the development of novel anti-invasive/antiangiogenic therapies. Here, we examine the expression of ADAMTS-8, a secreted protease with antiangiogenic properties, in brain tissues. Using quantitative RTpolymerase chain reaction (PCR), high, equivalent expression of ADAMTS-8 was found in normal whole brain, cerebral cortex, frontal lobe, cerebellum and meninges. ADAMTS- 8 expression in 34 brain tumours (including 22 high-grade gliomas) and four glioma cell lines indicated at least two-fold reduction in mRNA compared to normal whole brain in all neoplastic tissues, and no detectable expression in 14 out of 34 (41\%) tumours or four out of four (100\%) cell lines. In contrast, differential expression of TSPI and VEGF was seen in nine out of $15(60 \%)$ and seven out of $13(54 \%)$ tumours, with no relationship in the expression of these genes. Immunohistochemistry and Western analysis indicated downregulation of ADAMTS-8 protein in $>77 \%$ tumours. Methylationspecific PCR analysis of ADAMTS-8 indicated promoter hypermethylation in one out of 24 brain tumours (a metastasis) and three out of four glioma cell lines suggesting an alternative mechanism of downregulation. These data suggest a role for ADAMTS- 8 in brain tumorigenesis, warranting further investigation into its role in regulation of tumour angiogenesis and local invasion.
\end{abstract}

British Journal of Cancer (2006) 94, I I86-| | 93. doi:I0.1038/sj.bjc.6603006 www.bjcancer.com

Published online 28 March 2006

(c) 2006 Cancer Research UK

Keywords: ADAMTS-8; glioma; brain tumours; angiogenesis; invasion

The ADAMs and ADAMTS gene families encode related proteins characterised by an ADAM-like protease domain ( $a$ disintegrin and metalloprotease), and distinguished by one or more thrombospondin motifs (TS) in ADAMTS (review by Porter et al, 2005). The ADAMTS genes have varying functions, including inhibition of angiogenesis (-TS-1, -TS-8)(Vazquez et al, 1999), cleavage of the matrix proteoglycans aggrecan, versican and brevican (-TS-1, -4 , $-5,-8$ and -15)(AKA the 'aggrecanases')(Matthews et al, 2000; Collins-Racie et al, 2004; Porter et al, 2005), collagen processing (TS-2, -3 and -14)(Colige et al, 1995; Colige et al, 1997; Fernandes et al, 2001; Wang et al, 2004) and blood coagulation homeostasis (TS-13)(Zheng et al, 2001). The ADAMTS proteins are secreted proteases, some of which bind to the extracellular matrix (ECM), unlike the ADAMs proteases that are mostly transmembrane proteins. ECM binding, substrate recognition and cleavage are mediated through the central and C-terminal TS repeats and the spacer region (Kuno and Matsushima, 1998; Tortorella et al, 2000).

ADAMTS- 8 and TS- 1 are the only two members of the ADAMTS family known to have antiangiogenic properties. They have been shown to specifically inhibit endothelial cell (EC) proliferation in vitro, suppress FGF-2-induced vascularisation in the cornea pocket assay, and inhibit VEGF-induced angiogenesis in the chorioallantoic membrane (CAM) assay (Vazquez et al, 1999). In addition,

*Correspondence: Dr JR Dunn; E-mail: julie.dunn@ccrt.nhs.uk Received 12 September 2005; revised 13 January 2006; accepted 23 January 2006; published online 28 March 2006
ADAMTS-1 can bind VEGF $_{165}$, limiting its bioavailability; this binding is mediated by the C-terminal region of ADAMTS-1 (Luque et al, 2003). The function of VEGF on ECs is thus negatively modulated, and $\mathrm{VEGF}_{165}$, once bound, is unable to activate its receptor (VEGFR2).

In contrast to ADAMTS-1, ADAMTS-8 has a narrow tissue distribution and human normal tissue showing moderate to high levels includes adult and foetal lung, aorta, brain, foetal heart, foetal kidney, appendix and bladder; both genes are expressed in adult human normal brain (Vazquez et al, 1999; Collins-Racie et al, 2004). There is evidence of modulation of expression of several of the ADAMTS genes in cancer, with significant downregulation (two-fold or lower) of ADAMTS-8 in non-small-cell lung cancer (NSCLC) (Heighway et al, 2002; Dunn et al, 2004) and hypermethylation of the promoter region being a possible mechanism of gene silencing (Dunn et al, 2004). In comparison to non-neoplastic mammary tissue ADAMTS- 8 mRNA is also significantly downregulated in breast carcinomas (Porter et al, 2004). In contrast, ADAMTS-4 (aggrecanase-1) and TS-5 (aggrecanase-2) are upregulated in glioblastomas (GBMs), with a possible role in increased degradation of brevican thereby increasing invasive potential (Nakada et al, 2005; Held-Feindt et al, 2006).

Glioblastomas remain one of the most lethal neoplasms, due in part to their invasive nature and striking resistance to current therapies. There is currently a quest for a greater understanding of the biology of angiogenesis and invasion in gliomas with a view to the discovery of antiangiogenic/anti-invasive molecules that could 
be of therapeutic use in prolonging survival. ADAMTS- 8 protein has a more powerful antiangiogenic effect than thrombospondin-1 (TSP1) or endostatin (Vazquez et al, 1999). The aim of this study was to investigate the expression of ADAMTS-8 in high-grade gliomas and other brain tumours, and compare this with the expression of other well-characterised angiogenesis related genes TSP1 and VEGF.

\section{MATERIALS AND METHODS}

\section{Tissues and cell lines}

Snap frozen tumour tissue for 41 resected brain tumours comprising 25 high-grade gliomas (20 glioblastoma WHO grade IV (GBM), two oligoastrocytoma WHO grade III (OAIII), one oligodendroglioma WHO grade III (OIII), one astrocytoma WHO grade III (AIII), one ependymoma WHO grade III (EIII)), five meningiomas WHO grade I, nine metastases, one haemangioblastoma, one medulloblastoma and one sample of non-neoplastic temporal lobe (from epilepsy surgery) were obtained for analysis from the Walton Centre for Neurology and Neurosurgery, Liverpool with full ethical approval. Intrinsic brain tumours were diagnosed according to the WHO histopathology classification (Kleihues and Sobin, 2000). For each case, one whole frozen tumour tissue fragment $\left(\sim 0.5 \mathrm{~cm}^{3}\right)$ was cut on a cryostat as follows: $10 \times 30 \mu \mathrm{m}$ sections cut for extraction of RNA/DNA/ protein, followed by a $5 \mu \mathrm{M}$ section for $\mathrm{H} \& \mathrm{E}$ staining and pathological examination. All tumours were confirmed to contain at least $70 \%$ neoplastic cells.

Normal brain total RNAs were purchased from BD Biosciences (whole brain), and AMS Biotechnology (cerebellum, cerebral cortex, cerebral meninges and frontal lobe). Normal brain DNAs from two separate donors were purchased from AMS Biotechnology. A non-neoplastic temporal lobe sample (from epilepsy surgery) was used in the Western and methylation analysis.

Four glioma cell lines U373, T98G, Hs683 and U87MG used in the $\mathrm{RT}$ - polymerase chain reaction (PCR) and methylation assays were obtained from ECACC and ATCC.

\section{Genomic DNA extraction}

Genomic DNA was extracted from $10 \times 30 \mu$ m tissue sections using the Qiagen DNeasy ${ }^{\mathrm{TM}}$ Tissue kit according to the manufacturer's instructions.

Genomic DNA was extracted from cell lines using the Nucleon BACC1 kit according to the manufacturer's instructions.

\section{RNA extraction and cDNA synthesis}

Total RNA was extracted from $10 \times 30 \mu \mathrm{m}$ frozen tissue sections using the Qiagen ${ }^{\mathbb{R}}$ Rneasy Mini RNA extraction kit, following the manufacturer's protocol. RNA was aliquotted into $1-2 \mu \mathrm{g}$ amounts for subsequent Dnase treatment using Invitrogen Dnase I Amplification Grade. cDNA synthesis was performed in $20 \mu \mathrm{l}$ reactions using Invitrogen Superscript ${ }^{\mathrm{TM}}$ Reverse Transcriptase (RT), and oligo-dT primers (Invitrogen). For each sample, $500 \mathrm{ng}$ of RNA was used for cDNA synthesis and the remaining $500 \mathrm{ng}$ for a negative control (no RT). All new cDNA samples were diluted $20 \times$ then $5 \mu$ l of this dilution was amplified using cDNA specific PCR primers for the $\beta$-actin housekeeping gene to verify successful reverse transcription of sample cDNA with no genomic contamination (indicated by PCR product size).

\section{Quantitative (real-time) PCR}

Quantitative PCR (qPCR) assay of ADAMTS-8 expression in whole brain, cerebral cortex, frontal lobe, cerebellum, meninges and lung was undertaken to assess normal levels of the mRNA. Threshold cycles $\left(C_{\mathrm{t}} \mathrm{s}\right)$ were similar in all the brain regions tested therefore we used whole brain as the calibrator tissue in all subsequent qRTPCR experiments. For comparison, the expression of thrombospondin-1 (TSP1) and vascular endothelial growth factor (VEGF) was studied in a subset of cases $(n=26, n=24$, respectively).

To compare the relative expression levels of ADAMTS-8, TSP1 and $V E G F$ in normal whole brain to levels in multiple brain tumour tissues, we have used the comparative $\mathrm{C}_{t}$ method (Livak and Schmittgen, 2001) in which the expression of the test gene and a selected endogenous control gene (Histone H3) are measured in separate tubes. Normal whole brain cDNA was used as the calibrator tissue in each qPCR, which was carried out in an iCycler machine (BioRad). All PCR reactions were carried out in triplicate and each experiment was repeated at least once.

The threshold of detection for all primers was such that product could be detected from an initial RNA target of $50 \mathrm{ng}$ in the RT reaction. Primer sequences, positions and efficiencies were as follows. ADAMTS-8 primers spanned exons 3 and 4 (forward: $5^{\prime}$ AAC AAA AGC TGC TCC GTG AT-3'; reverse: 5'-TCT GGT TCA GGT GGA CGA AC- $3^{\prime}$ ); TSP1 primers spanned exons 22 and 23 (forward: $5^{\prime}$ AGC AGG GTG CTA TTG TGA GG $3^{\prime}$; reverse: $5^{\prime} \mathrm{CCT}$ TAG TGC TTT GGC CTC TG-3'); VEGF primers spanned exons 3 and 4 (forward: 5'AGA AGG AGG AGG GCA GAA TC- ${ }^{\prime}$; reverse: $5^{\prime}$ CAC ACA GGA TGG CTT GAA GA) to detect all VEGF isoforms ; Histone $H 3$ primers spanned exons 3 and 4 (forward: $5^{\prime}$ CCACTGAACTTCTGATTCGC-3' ${ }^{\prime}$; reverse: $5^{\prime}$ AAGACATCCAGCTA GCACGC- $\left.3^{\prime}\right)$. Twenty microlitres of PCR reactions contained $5 \mu \mathrm{l}$ of $20 \times$ diluted cDNA (equivalent to $\sim 6.25 \mathrm{ng}$ of starting RNA), $10 \mu \mathrm{IQ}^{\mathrm{TM}}$ SYBR $^{\circledR}$ Green Supermix Buffer, $2 \mu \mathrm{l}$ forward and reverse

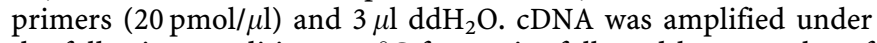
the following conditions: $95^{\circ} \mathrm{C}$ for $3 \mathrm{~min}$, followed by 48 cycles of $94^{\circ} \mathrm{C}$ for $30 \mathrm{~s}$, Tm (ADAMTS- $8, T S P 1=68^{\circ} \mathrm{C}, V E G F=64^{\circ} \mathrm{C}$ ) for $30 \mathrm{~s}, 72^{\circ} \mathrm{C}$ for $30 \mathrm{~s}$ and a final step at $95^{\circ} \mathrm{C}$ for $30 \mathrm{~s}$ followed by collection of melt curve data under standard settings. Finally, $5 \mu \mathrm{l}$ of the resulting PCR product was visualised by electrophoresis through a $3 \%$ agarose gel containing ethidium bromide. Melt curves for the qPCR reactions and a single band of the correct size on the gels were used to verify the correct product in each PCR. In addition, the ADAMTS- 8 sequence in normal whole brain, lung and four brain tumours was verified by direct sequencing of the PCR product and BLAST analysis. Where mRNA expression data is described, downregulation has been designated $0.5 \times$ or less, and upregulation as $2 \times$ or more.

\section{Immunohistochemical analysis of ADAMTS-8}

Immunohistochemistry (IHC) was performed as described previously (Dunn et al, 2004) using an ADAMTS-8 N-terminal antibody (1:500 dilution) (ADAMTS-8 AB-1, Oncogene Research Products; cat\#PC508) and $5 \mu \mathrm{m}$ sections cut from formalin fixed, paraffin-embedded blocks from the same tumour resections. Each run included tissue sections from brain tumours, normal cerebellum and a positive control (normal human stomach) incubated with primary antibody, and a negative control with no primary antibody for each section. Protein expression was scored by a consultant neuropathologist (DDP) blinded to clinical details for each case; each section was assessed as to the type of cells staining, intracellular distribution and intensity of staining. Intensity was defined as negative $(-)$, equivocal $(+/-)$, or positive (with $>10 \%$ neoplastic cells staining,,+++ and $+++)$. Downregulation of ADAMTS- 8 compared to cerebellum is indicated by scores of,$-+I-$ and + .

\section{Total protein extraction}

A $4-5 \mathrm{~mm}^{3}$ piece of brain tissue was homogenised on ice in $100 \mu \mathrm{l}$ extraction buffer ( $1 \mathrm{~m}$ Tris- $\mathrm{HCl} \mathrm{pH} 7.5,1.5 \mathrm{M} \mathrm{NaCl}, 10 \%$ SDS, $5 \%$ NP40) containing one Protease Inhibitor tablet per ml buffer 
(Roche) using a micro-pestle. All homogenates were vigorously shaken at 3000 r.p.m. at room temperature for $30 \mathrm{~min}$ before centrifugation at 13000 r.p.m. for $10 \mathrm{~min}$. Protein supernatants were combined with laemmli sample buffer (Bio Rad) heated at $100^{\circ} \mathrm{C}$ for $10 \mathrm{~min}$ then plunged into ice immediately prior to gel electrophoresis.

\section{Western blot analysis of ADAMTS-8}

Total protein extracts (SW480 $=6 \mu \mathrm{g}$, non-neoplastic temporal lobe $=10 \mu \mathrm{g}$, tumours $=30 \mu \mathrm{g}$ ) were separated on $8 \%$ Tris-HEPESSDS precast polyacrylamide gels (Pierce Precise ${ }^{\mathrm{TM}}$ Protein Gels, Perbio Science UK Ltd, Northumberland, UK). Each gel was divided into two halves ( $\mathrm{A}$ and $\mathrm{B}$ ), where both portions received an identical sample loading and where B subsequently served as a negative control blot, being incubated in blocking buffer without primary antibody. Gels were equilibrated in renaturation buffer

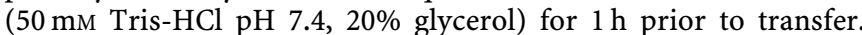
Proteins were then electrophoretically transferred to a nitrocellulose membrane, which was subsequently incubated overnight in blocker (PBS-T, 5\% Marvel) at room temperature with shaking. Immunoreactive products were then detected by incubating for $1 \mathrm{~h}$ with ADAMTS-8 antibody (1:1000 dilution in blocker). Membranes were incubated for $1 \mathrm{~h}$ with a $1: 3000$ dilution (in blocker) of secondary antibody (HRP labelled anti-rabbit raised in donkey, Amersham NA 934VS), followed by chemiluminescent detection of specific proteins using Amersham ECL Advance kit and standard autoradiography procedures.

\section{Methylation analysis of the ADAMTS-8 promoter region}

One microgram of genomic DNA was chemically modified by treatment with sodium bisulphite using the CpGenome ${ }^{\mathrm{TM}}$ DNA modification kit from Intergen (Intergen Company, Oxford, OX4 4GA, UK, Catalog\#S7820) according to the kit protocol. The modified, cleaned DNA was resuspended in $50 \mu \mathrm{l}$ TE buffer, aliquotted and stored at $-80^{\circ} \mathrm{C}$. A cMSP assay was used to assess the methylation status of the ADAMTS-8 promoter region as described previously (Dunn et al, 2004). Polymerase chain reaction products (control: $299 \mathrm{bp}$, methylation specific: 169 bp) were analysed on $4 \%$ agarose gels containing ethidium bromide.

\section{Statistical analysis}

Results are expressed as means. Statistical analysis was performed using SPSS (version 13.0). Differences between groups were evaluated by the Mann-Whitney test. mRNA and immunocytochemistry data were compared using Spearman's correlation test. A probability $(P)$ value $<0.05$ was considered significant.

\section{RESULTS}

\section{ADAMTS-8 expression}

$m R N A$

Non-neoplastic tissues: Gene expression analysis using RT - PCR showed equivalent levels of ADAMTS- 8 in normal whole brain, frontal lobe, cerebral cortex and meninges, with higher expression in normal lung (Figure 1).

Brain tumours: Hundred percent of cases showed lower expression of ADAMTS-8 compared with normal brain. ADAMTS-8 was not detectable in 14 out of $34(41 \%)$ brain tumours, and downregulated between two- and a 1000-fold compared to normal brain in 21 out of $34(62 \%)$ (Figure 1, Table 1). All gliomas showed at least two-fold downregulation of expression, with eight out of 22 $(36 \%)$ tumours (all GBM) showing $>40$-fold downregulation (Figure 1). Only five grade III gliomas with varying histological

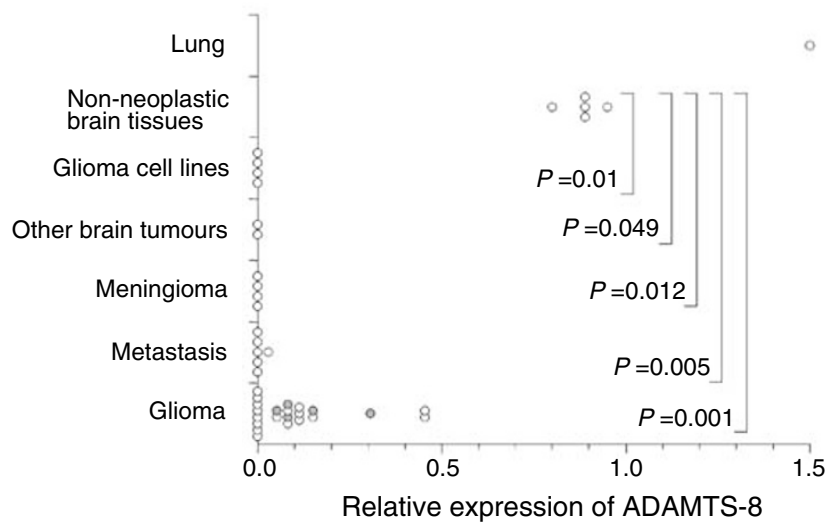

Figure I Expression of ADAMTS-8 in brain tissues, glioma cell lines and lung relative to normal whole brain by quantitative RT-PCR. Grade III gliomas are indicated by shaded circles.

subtypes were available for study, limiting comparison between different histopathological types of glioma. With the available series, GBM and grade III gliomas showed an overlapping range of relative expression of ADAMTS-8 (GBM 0.0001-0.45; grade III gliomas $0.05-0.3)$ (Figure 1), and no significant difference between grades. When analysed separately, both GBMs and grade III gliomas showed a significant downregulation of ADAMTS-8 compared to the non-neoplastic brain tissues (Mann-Whitney test: GBM $P=0.001$, grade III $P=0.009)$. ADAMTS- 8 was not detectable in three out of four meningiomas, four out of six metastases and four out of four glioma cell lines tested (Table 1). Despite the small number of cases, metastases and meningiomas were more likely to have lower ADAMTS-8 expression than gliomas (Mann - Whitney test: metastases $P=0.013$, meningiomas $P=0.031)$.

\section{Protein}

Immunohistochemistry: Immunohistochemistry analysis was carried out in formalin fixed, paraffin-embedded brain tissues comprising 35 brain tumours ( 25 gliomas (20 GBM, five grade III tumours), seven metastases and three meningiomas) and one normal cerebellum.

Non-neoplastic brain tissues: Staining in normal stomach sections, which were used in this study as a positive control, was punctate and confined to the secretory type cells of the epithelial layer, as found in normal lung (Dunn et al, 2004). In normal cerebellum, the Purkinje and molecular cell layers showed focal cytoplasmic ADAMTS-8 staining of neurons $(++)$ (Figure 2A, Table 1$)$, and in the white matter, astrocytes were positive $(++)$ for ADAMTS-8 protein (Figure 2B).

Brain tumours In tumour sections, some staining was observed in reactive glia, vascular endothelium and some lymphocytes (Figure 2C and E). ADAMTS-8 protein in neoplastic cells was downregulated in the majority of tumours (27 out of $35,77 \%$ ) compared to cerebellum or uninvolved 'normal' non-neoplastic brain present within some tumour sections (Table 1). Most of the tumours (24 out of $35,69 \%$ ) showed some positive diffuse cytoplasmic staining for ADAMTS-8, with the exception of two mucinous-type metastases of gastrointestinal origin that showed focal punctate cytoplasmic staining similar to that seen in cerebellum, uninvolved brain, stomach and normal lung (Table 1)(Dunn et al, 2004). One tumour (GBM) was negative for ADAMTS-8 (Figure 2F, Table 1). Eleven gliomas (11 out of 24, $46 \%)$ showed variable nuclear staining (Table 1). Ten tumours scored + I-: three GBM, three grade III gliomas, three meningiomas and a non-mucinous type metastasis of breast origin (Table 1). 
Table I Summary of ADAMTS-8 data in brain samples, showing case identifier, histology, expression of mRNA by qRT-PCR, expression of protein by immunohistochemistry and Western blotting, and the methylation status of the promoter region (methyl)

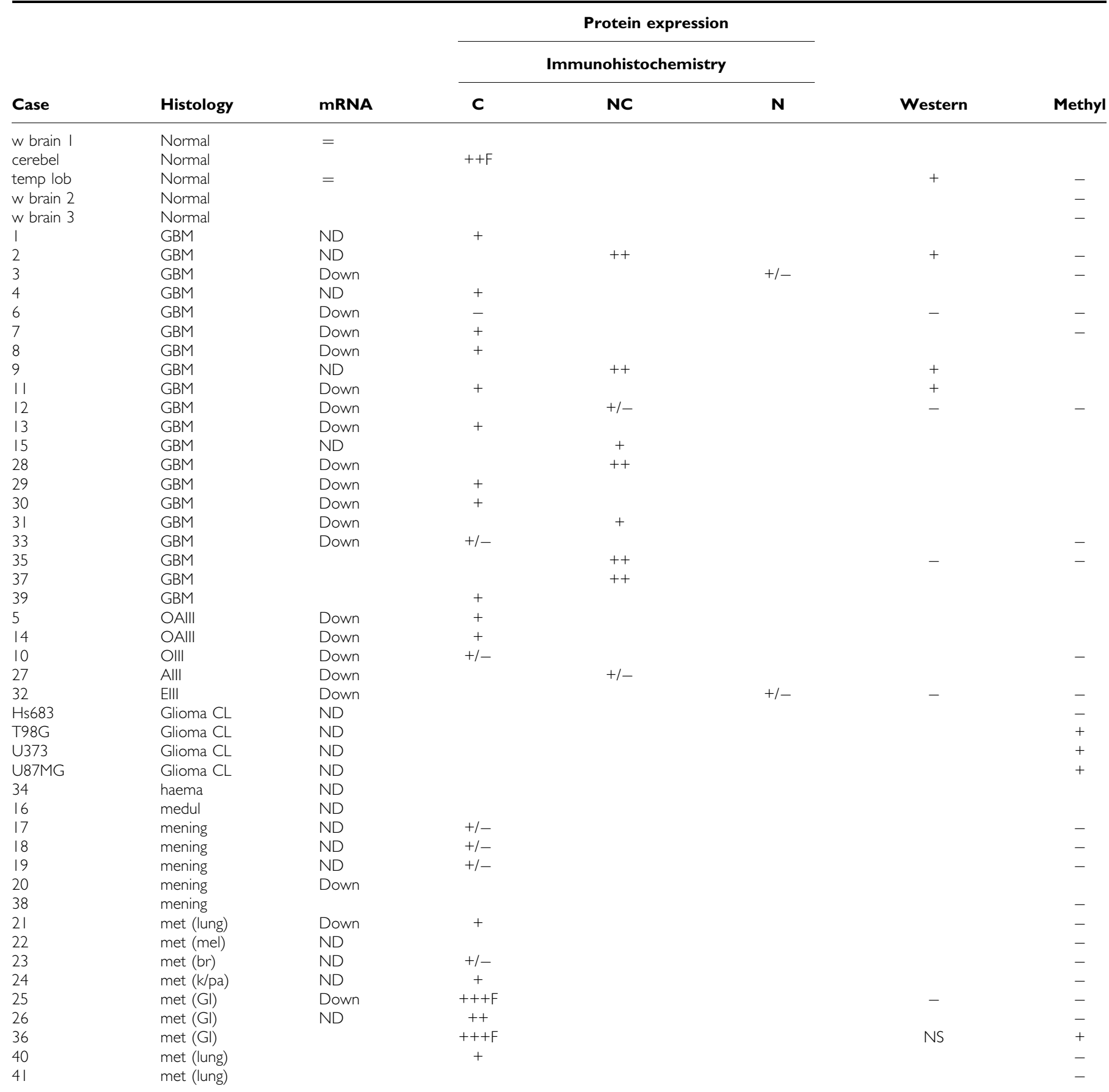

Expression of mRNA data relative to normal whole brain and was equivalent $(=)$, not detectable (ND) or downregulated (Down). Immunohistochemistry data show intensity of staining ( - indicates negative; +/-, equivocal; +/++/+++, positive) the subcellular location of the stain (C indicates cytoplasmic; NC, nuclear and cytoplasmic; N, nuclear) and staining pattern, which was diffuse unless described as focal (F). Western data indicates the presence $(+)$ or absence $(-)$ of a $98 \mathrm{kDa}$ band. Methylation data indicate promoter hypermethylation $(+)$ or no methylation $(-)$. w brain = whole brain; cerebel=cerebellum; temp lob=temporal lobe: GBM=glioblastoma; $\mathrm{OA}=$ oligoastrocytoma; $\mathrm{O}=$ oligodendroglioma; $\mathrm{A}=$ astrocytoma; $\mathrm{E}=$ ependymoma; haema = haemangioblastoma; medul=medulloblastoma; mening =meningioma; met =metastatic tumour, followed by origin of primary tumour $-\mathrm{br}=$ breast; $\mathrm{k}=$ kidney; $\mathrm{mel}=$ melanoma; $\mathrm{pa}=$ pancreas; $\mathrm{Gl}=$ gastrointestinal tract; $\mathrm{NS}=$ nonspecific bands.

Eleven GBM, two grade III gliomas and three metastases scored + (Table 1). Thus $70 \%$ GBM, $100 \%$ grade III gliomas, $100 \%$ meningiomas and 57\% metastases showed decreased expression of the ADAMTS- 8 protein compared to normal brain. There was no clear correlation between mRNA and immunopositivity (Spearman Correlation: all cases $P=0.6$, gliomas $P=0.109$ ). Eight tumours (eight out of $35,23 \%$ ), all with downregulated mRNA, showed upregulation or equivalent staining to that in uninvolved or non-neoplastic brain, including five GBM (with variable nuclear staining) and three mucinous type metastases of gastrointestinal origin (Figure $2 \mathrm{C}-\mathrm{E}$, Table 1). Of the tumours with no detectable mRNA, seven out of 11 were immunopositive. Overall, 27 out of 35 (77\%) tumours including 20 out of $25(80 \%)$ gliomas were considered to show downregulation of the protein. 

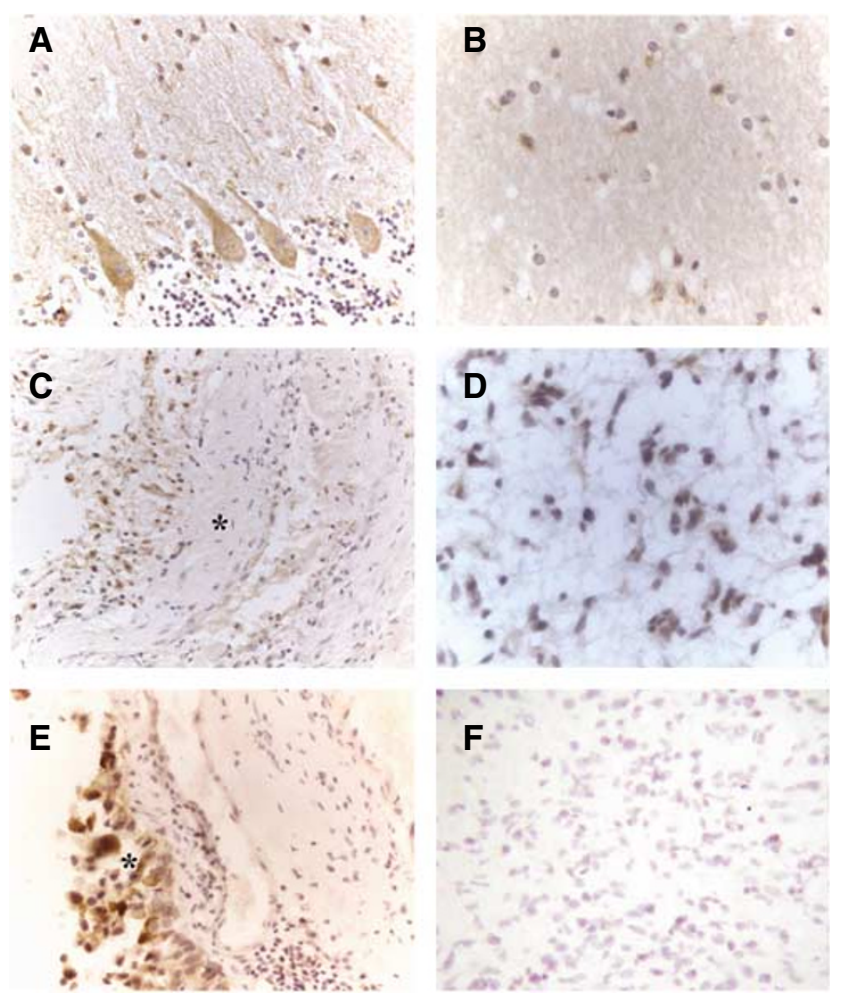

Figure 2 Expression of ADAMTS-8 protein by immunohistochemistry of formalin-fixed, paraffin-embedded brain tissues. (A) Normal cerebellar cortex (original magnification $\times 400$ ). Positive cytoplasmic staining $(++)$ of neurons in the molecular and Purkinje cell layers. (B) Normal cerebellar white matter (original magnification $\times 630$ ). Positive cytoplasmic staining $(++)$ of glial cells, most likely astrocytes. $(\mathbf{C})$ and (D) GBM (case no.28). (C) (original magnification $\times 400$ ) shows positive diffuse cytoplasmic staining $(+/++)$ of tumour cells (left of image) adherent to a blood vessel (right side). The tumour cells show cytoplasmic expression and weaker, variable nuclear expression. The vascular endothelium shows weak expression and the vascular wall stroma (fibroblast and smooth muscle*) appears negative. $(\mathbf{D})$ (original magnification $\times 630$ ) shows malignant glial cells with cytoplasmic and some variable nuclear expression. (E) Metastatic carcinoma of gastrointestinal tract origin (case no. 25)(original magnification $\times 400)$. Strong focal cytoplasmic expression* $(+++)$ by malignant epithelial cells. Adjacent stroma contains fibroblasts (negative), lymphocytes (weak, variable staining) and vessels (with weak endothelial staining). (F) GBM case no. 6) (original magnification $\times 630$ ). Negative staining of tumour cells.

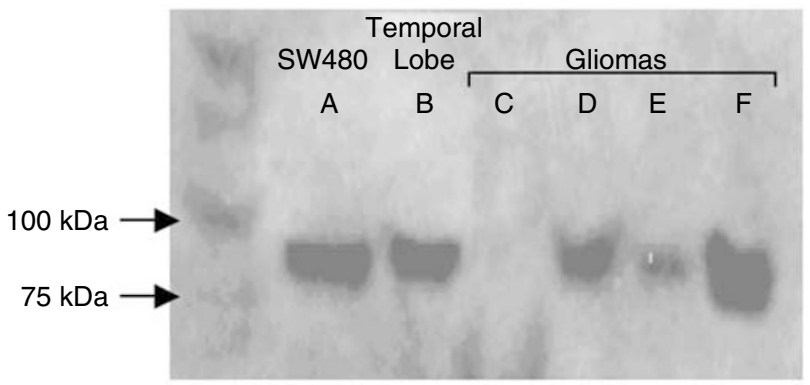

Figure 3 Chemiluminescent detection in Western analysis of full-length ADAMTS- 8 protein $(98 \mathrm{kDa})$ in total protein tissue extracts from normal temporal lobe and four GBMs, and commercial total protein extract from SW480 cell line (human colon carcinoma)(control). Protein loading amounts: $\mathrm{SW} 480=15 \mu \mathrm{g}$, normal brain $=30 \mu \mathrm{g}$, tumours $=90 \mu \mathrm{g}$.
Western blot Western blot analysis of the control SW480 cell line, non-neoplastic temporal lobe tissue and nine brain tumour total protein extracts (including five strong expressers of ADAMTS- 8 by IHC analysis, see Table 1) using the same ADAMTS- 8 primary antibody revealed one specific band at $\sim 98 \mathrm{kDa}$ in the SW480 control, temporal lobe and three glioma extracts (all IHC positive) (Figure 3, Table 1). A protein loading of three times that of nonneoplastic brain was required to see any bands from the tumour extracts. The expected size for ADAMTS- 8 using this antibody and the SW480 protein is $98 \mathrm{kDa}$. No specific bands were detected in the remaining tumour extracts (Table 1).

\section{Expression of TSP1 and VEGF in brain tumours}

$m R N A$ Quantitative RT-PCR analysis showed that both genes were expressed in all cases, with both TSP1 and VEGF being differentially expressed compared to normal brain in $62 \%$ (16 out of 26 ) and $63 \%$ (15 out of 24 ) of cases, respectively (Figure 4 ). There was no correlation between the expression patterns of ADAMTS-8, TSP1 and VEGF. In summary, TSP1 was upregulated in $42 \%$ ( 11 out of 26 ), downregulated in $19 \%$ (five out of 26 ) and unchanged in $38 \%$ (10 out of 26 ) of tumours tested. VEGF was upregulated in $38 \%$ (nine out of 24 ), downregulated in $25 \%$ (six out of 24) and unchanged in $38 \%$ (nine out of 24 ). In ten tumours that showed vascular proliferation typical of high-grade gliomas on examination of the H\&E sections, nine also showed up-regulation of both VEGF and TSP1, accompanied by at least eight-fold downregulation of ADAMTS-8.

\section{ADAMTS-8 promoter methylation status}

There was no evidence of methylation of the ADAMTS- 8 promoter in 23 out of $24(96 \%)$ of the tumours, one out of four cell lines or in the three normal samples (Table 1). One tumour (a bowel metastasis) and three out of four glioma cell lines showed promoter methylation using this assay (Figure 5, Table 1).

\section{DISCUSSION}

Brain tumours, especially GBM, have a propensity for diffuse infiltration of brain parenchyma that contributes to a high morbidity and mortality. The ability of tumour cells to infiltrate surrounding brain tissue is reliant on their passage through the ECM, facilitated in part by the actions of proteases. Similarly, angiogenesis (also essential to tumour progression) is reliant on the positive and negative regulation of proteases such as the $M M P s, A D A M s$ and ADAMTS (review by Handsley and Edwards, 2005).

Until recently, the ADAMs and ADAMTS genes were relatively understudied in brain tumours (and other cancers), however, recent reports have suggested roles for ADAMTS-4, TS-5 (HeldFeindt et al, 2006; Nakada et al, 2005) and ADAM-12 (Kodama et al, 2004) in GBM, where these proteases are overexpressed. In contrast, we have shown that the expression of ADAMTS- 8 is downregulated in brain tumours relative to normal brain. Messenger RNA levels were reduced at least two-fold in $100 \%$ (34 out of 34) tumours and four out of four glioma cell lines tested, and protein data (IHC and Western) also suggested downregulation of ADAMTS-8. IHC analysis indicated decreased levels of protein in $77 \%$ of brain tumours tested compared to nonneoplastic tissue, and in Western blots, protein was undetectable in $67 \%$ of tumours and indicated a greater threshold of detection in 33\%. Our data are consistent with other reports of ADAMTS-8 downregulation in cancers (Heighway et al, 2002; Dunn et al, 2004; Porter et al, 2004), suggesting there may be opposing physiological roles for individual ADAMTS family members in carcinogenesis. For example the predominant role of ADAMTS-8 may be 


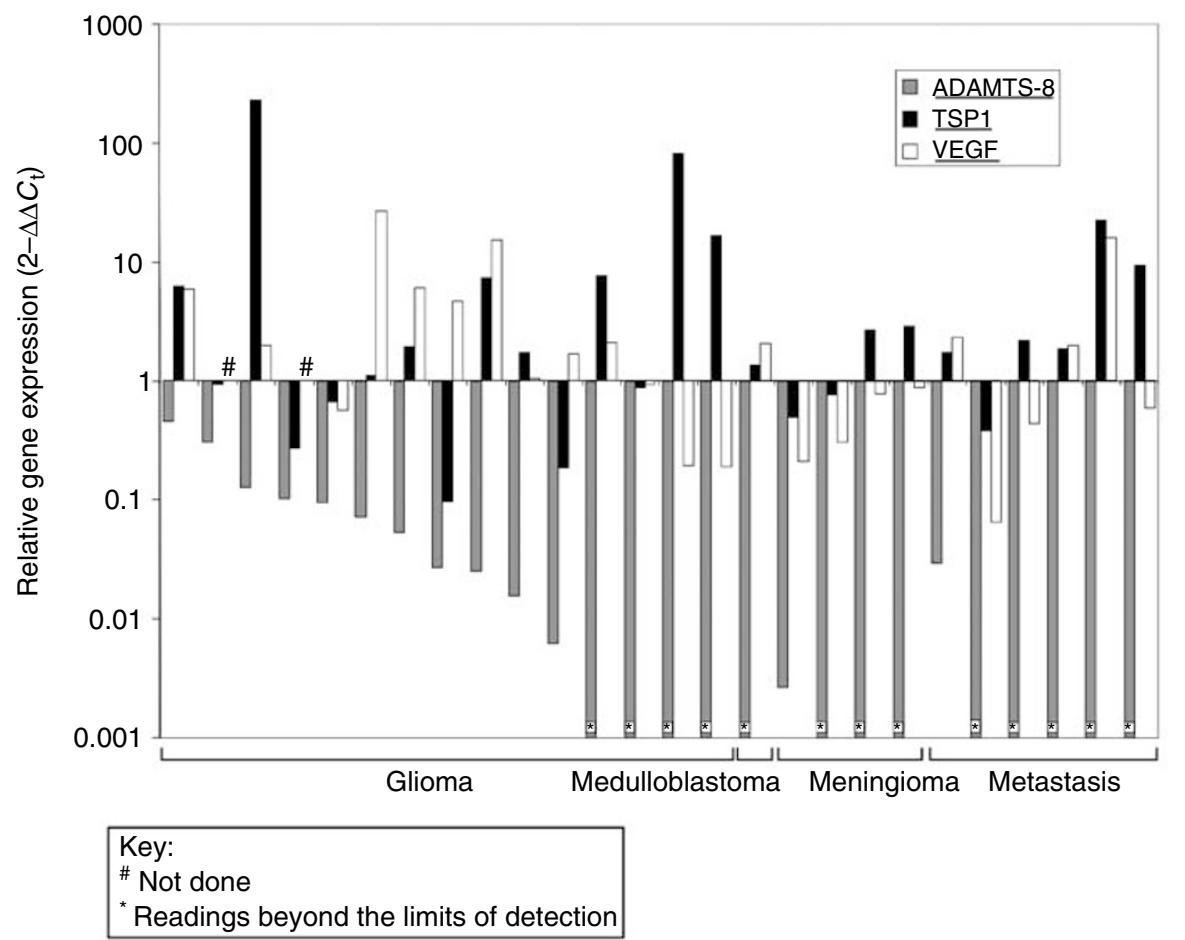

Figure 4 Expression of ADAMTS-8, TSPI and VEGF in brain tumours relative to normal whole brain by quantitative RT-PCR. Y-values are shown on a log scale where I signifies expression equivalent to that observed in normal whole brain.
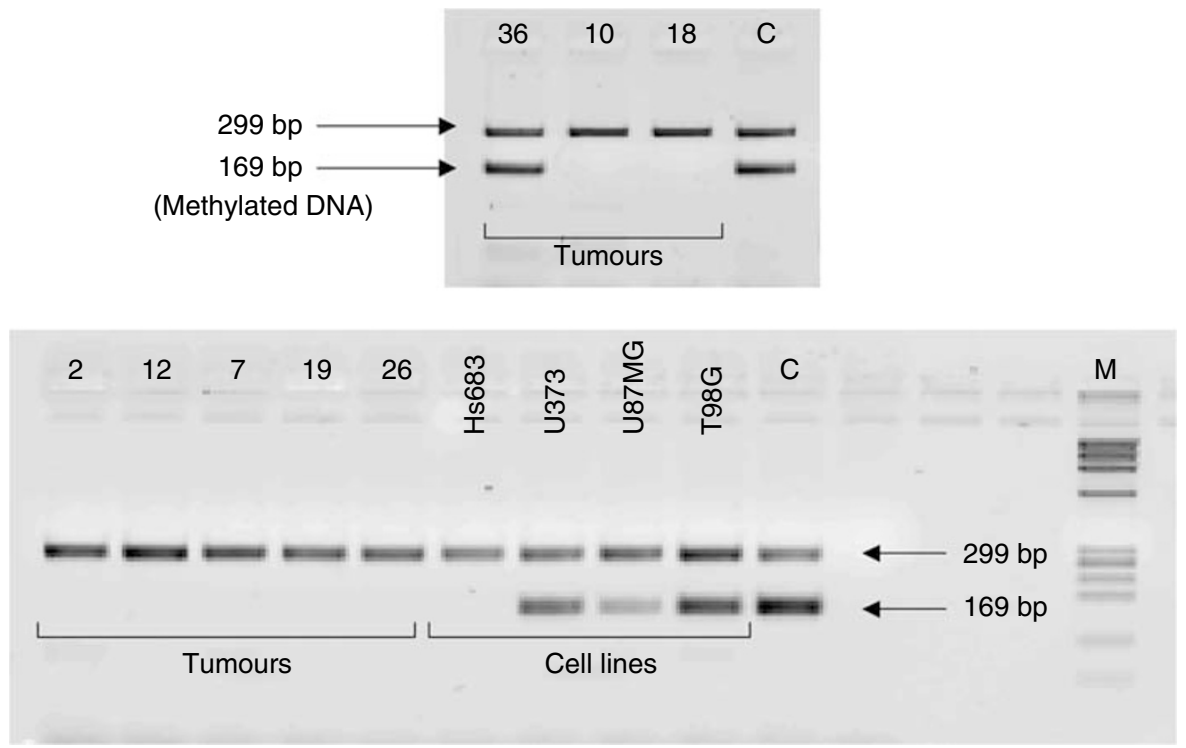

Figure 5 Competitive methylation-specific PCR (c-MSP) analysis of brain tumours and glioma cell lines. The presence of the methylation-independent control fragment (299 bp) confirms sufficient amounts of converted DNA in the reaction, while the presence of the methylation-specific product (I69 bp) demonstrates the existence of methylated copies of DNA. DNAs from case 36 (metastatic carcinoma of Gl origin) and glioma cell lines U373, U87MG and T98G showed methylation of ADAMTS-8, while cases 10 (OAIII), 2 (GBM), 12 (GBM), 7 (GBM), I8, 19 (meningiomas) and 26 (metastatic tumour of gastrointestinal/lung origin), and cell line HS683 showed no methylation. C, universally methylated DNA control; M, DNA molecular weight marker.

antiangiogenesis, necessitating silencing in tumours, whereas the predominant role for ADAMTS-4 and TS-5 may be ECM degradation necessitating up-regulation. Studies of the MMPs have shown that some family members act as angiogenic molecules and some as antiangiogenic (review by Handsley and Edwards, 2005).
The antibody used in this study recognises a binding site within the prodomain and Western data revealed a $98 \mathrm{kDa}$ ADAMTS- 8 band common to both tumour and normal brain, consistent with the size of the full-length secreted protein after removal of the signal peptide. Using a cDNA probe containing a fragment of $A D A M T S-8$ bearing a portion of the disintegrin domain and the 
first TS-type repeat, positive expression has been demonstrated in human normal whole brain, and various brain regions (CollinsRacie et al, 2004). However, other documented forms (79 and $64 \mathrm{kDa}$ )(Vazquez et al, 1999) of ADAMTS-8, which retain antiangiogenic activity after proteolytic cleavage, may be present in normal and tumour brain tissues, would not be detected in the present study. ADAMTS-1 processing resulting in the release of the C-terminal end does not affect the catalytic function of the protease (Rodriguez-Manzaneque et al, 2000), with both processed forms having the ability to block EC proliferation in a dose dependent manner. Moreover, it is suggested that processing might release two fragments with distinct/independent functions in the ECM.

IHC data indicated the presence of ADAMTS- 8 protein in the normal cerebellum and lower levels of protein in the majority $(77 \%)$ of tumours tested (Table 1$)$. Two mucinous type metastatic tumours of gastrointestinal origin showed strong staining $(+++)$ for ADAMTS-8, although notably, neither of these cases gave a specific band in the Western analysis, which could be due to the lower proportion of ADAMTS-8 expressing cells within these samples. Most of the gliomas exhibited a diffuse cytoplasmic staining pattern and in addition $46 \%$ showed a variable nuclear stain. However, the Western data for two out of two samples with variable nuclear staining showed one band indicating specificity of the antibody at least under Western conditions. Overall the protein data for ADAMTS-8 suggest downregulation of the protein in the majority of brain tumours, although only further experimentation will determine the precise nature of this ADAMTS-8 protein.

Despite the downregulation of ADAMTS- 8 mRNA and protein seen in the majority of brain tumours studied, there was no clear correlation between protein and mRNA expression levels. All tumours had downregulation of mRNA, but this was associated with varying degrees of immunopositivity. These data may reflect the differing sensitivities of the RT-PCR and IHC assays, or suggest that $A D A M T S-8$ expression may be regulated via transcription as well as factors that influence protein stability, with a longer protein half-life in some cases.

The mechanism of downregulation of ADAMTS-8 in these brain tumours is unknown, but seems unlikely to be hypermethylation of the promoter region as observed in $58 \%$ (29 out of 50) of NSCLC (Dunn et al, 2004), since only one out of 24 tumours showed methylation using our assay. Notably, this tumour also showed hypermethylation in the promoter region of another gene situated within $20 \mathrm{~kb}$ on Chr11q25, and it is conceivable that this tumour contains an extensively methylated region of $\mathrm{C} 11 \mathrm{q} 25$. C11 $\mathrm{q}$ is not a region commonly showing deletion in LOH or CGH analysis in gliomas, however, there is evidence (from CGH analysis) of a $550 \mathrm{~kb}$-deleted region at $11 \mathrm{q} 13$ in low-grade oligodendrogliomas (Rossi et al, 2005).

No correlation was found in the expression patterns of ADAMTS-8, TSP1 and VEGF. It has been shown that VEGF is significantly overexpressed in GBMs (Plate et al, 1992; Shweiki et al, 1992), meningiomas, metastases and haemangioblastomas, however our data indicated up-regulation of $V E G F$ in only $38 \%$ of tumours. Munaut et al (2003) found 2-15-fold upregulation of VEGF mRNA in most (17 out of 20) GBMs, downregulation in two and equivalent expression in one, although the relative abundance of isoforms 165, 121, 189 and 145 varied, with 165 being the most abundant. Since our VEGF PCR primers were designed to detect all isoforms, the relative abundance of $V E G F$ isoforms in our samples was not assessed. However, if ADAMTS-8, like its counterpart TS1 , also binds $\mathrm{VEGF}_{165}$, ADAMTS-8 may sequester $\mathrm{VEGF}_{165}$, thus exerting an antiangiogenic effect. VEGF expression is upregulated in regions of hypoxia and localised to tumour vasculature, and in this study the expression of $V E G F$ was seen in cases where a vascular proliferation was noted. TSP1 was downregulated in the minority (19\%) of the tumours tested and its expression did not correlate with that of ADAMTS-8 (also antiangiogenic). It is known that although some genes involved in angiogenesis are segregated into proangiogenic or antiangiogenic, the real situation is far more complex. It has been shown that continuous expression of the antiangiogenic TSP1 in brain tumours can induce a more aggressive angiogenic phenotype by inducing VEGF expression (Filleur et al, 2001; Filleur et al, 2003). In hepatocellular carcinoma, TSP-1 protein expression (in vivo) is significantly associated with tumour invasiveness and progression (Poon et al, 2004). Furthermore, in GBM, it has been demonstrated that tumour perfusion was the same in TSP-1 transfected tumours and controls, and that although tumour growth in vivo is slowed by TSP-1 overexpression, tumours still reach a large size $\left(300 \mathrm{~mm}^{3}\right)$ (Kragh et al, 2002). Moreover, like VEGF, the expression of TSP1 was coincident with a vascular proliferation in nine out of 10 tumours. In hepatocellular carcinoma there is a significant relationship between tumour TSP1 levels and venous invasion even in patients with high and low tumour VEGF levels (Poon et al, 2004). It is thought that TSP1 expression in brain tumours is influenced by several factors including hypoxia, cell density (in vitro) and cell type (Tenan et al, 2000; Kawataki et al, 2000; Laderoute et al, 2000; Filleur et al, 2001; Naganuma et al, 2003).

The reduction in ADAMTS-8 expression was not tumour type specific, since 22 gliomas, four meningiomas, six metastases, one haemangioblastoma and one medulloblastoma were analysed. However, as yet, the possible role of ADAMTS-8 in brain tumour development remains unclear. There was no evidence to suggest that ADAMTS-8 expression is localised to the vasculature as for TSP1 and VEGF, or whether it is related to hypoxia. ADAMTS-8 is downregulated in GBM, and further future investigation in lowgrade and anaplastic gliomas that represent the various histological subtypes of glioma will reveal whether downregulation is an early event in gliomagenesis or, as for angiogenesis, may be associated with the transition from grade II to III.

In summary, the RT - PCR data suggest that in contrast to TSP1 and VEGF, the downregulation of ADAMTS-8 is a consistent event in the formation of brain tumours and is consistent with findings in other cancer types. Therefore, insight into its functional role and the biological events that regulate its expression is warranted. However, before we can ascertain whether ADAMTS-8 and/or related molecules represent potential therapeutic targets in gliomas, further investigation of the ADAMTS gene family will be necessary to elucidate their potential roles relating to angiogenesis, ECM degradation and invasion.

\section{ACKNOWLEDGEMENTS}

We thank Dr Lakis Liloglou for assistance with the DNA methylation assay. This work was kindly supported by the Clatterbridge Cancer Research Trust.

\section{REFERENCES}

Colige A, Beschin A, Samyn B, Goebels Y, Van Beeumen J, Nusgens BV, Lapiere CM (1995) Characterization and partial amino acid sequencing of a $107-\mathrm{kDa}$ procollagen I $N$-proteinase purified by affinity chromatography on immobilized type XIV collagen. J Biol Chem 270: 16724-16730
Colige A, Li SW, Sieron AL, Nusgens BV, Prockop DJ, Lapiere CM (1997) cDNA cloning and expression of bovine procollagen I $N$-proteinase: a new member of the superfamily of zinc-metalloproteinases with binding sites for cells and other matrix components. Proc Natl Acad Sci USA 94: 2374-2379 
Collins-Racie LA, Flannery CR, Zeng W, Corcoran C, Annis-Freeman B, Agostino MJ, Arai M, DiBlasio-Smith E, Dorner AJ, Georgiadis KE, Jin M, Tan XY, Morris EA, LaVallie ER (2004) ADAMTS-8 exhibits aggrecanase activity and is expressed in human articular cartilage. Matrix Biol 23: $219-230$

Dunn JR, Panutsopulos D, Shaw MW, Heighway J, Dormer R, Salmo EN, Watson SG, Field JK, Liloglou T (2004) METH-2 silencing and promoter hypermethylation in NSCLC. Br J Cancer 91: 1149-1154

Fernandes RJ, Hirohata S, Engle JM, Colige A, Cohn DH, Eyre DR, Apte SS (2001) Procollagen II amino propeptide processing by ADAMTS-3. Insights on dermatosparaxis. J Biol Chem 276: 31502-31509

Filleur S, Courtin A, Ait-Si-Ali S, Guglielmi J, Merle C, Harel-Bellan A, Clezardin P, Cabon F (2003) SiRNA-mediated inhibition of vascular endothelial growth factor severely limits tumor resistance to antiangiogenic thrombospondin-1 and slows tumor vascularization and growth. Cancer Res 63: 3919-3922

Filleur S, Volpert OV, Degeorges A, Voland C, Reiher F, Clezardin P, Bouck $\mathrm{N}$, Cabon $\mathrm{F}$ (2001) In vivo mechanisms by which tumors producing thrombospondin 1 bypass its inhibitory effects. Genes Dev 15: 1373- 1382

Handsley MM, Edwards DR (2005) Metalloproteinases and their inhibitors in tumor angiogenesis. Int I Cancer 115: 849-860

Heighway J, Knapp T, Boyce L, Brennand S, Field JK, Betticher DC, Ratschiller D, Gugger M, Donovan M, Lasek A, Rickert P (2002) Expression profiling of primary non-small cell lung cancer for target identification. Oncogene 21: 7749-7763

Held-Feindt J, Paredes EB, Blomer U, Seidenbecher C, Stark AM, Mehdorn HM, Mentlein R (2006) Matrix-degrading proteases ADAMTS4 and ADAMTS5 (disintegrins and metalloproteinases with thrombospondin motifs 4 and 5) are expressed in human glioblastomas. Int $J$ Cancer 118(1): $55-61$

Kawataki T, Naganuma H, Sasaki A, Yoshikawa H, Tasaka K, Nukui H (2000) Correlation of thrombospondin-1 and transforming growth factor-beta expression with malignancy of glioma. Neuropathology 20: $161-169$

Kleihues P, Sobin LH (2000) World Health Organization classification of tumors. Cancer 88: 2887

Kodama T, Ikeda E, Okada A, Ohtsuka T, Shimoda M, Shiomi T, Yoshida K, Nakada M, Ohuchi E, Okada Y (2004) ADAM12 is selectively overexpressed in human glioblastomas and is associated with glioblastoma cell proliferation and shedding of heparin-binding epidermal growth factor. Am I Pathol 165: $1743-1753$

Kragh M, Quistorff B, Tenan M, Van Meir EG, Kristjansen PE (2002) Overexpression of thrombospondin-1 reduces growth and vascular index but not perfusion in glioblastoma. Cancer Res 62: 1191-1195

Kuno K, Matsushima K (1998) ADAMTS-1 protein anchors at the extracellular matrix through the thrombospondin type I motifs and its spacing region. J Biol Chem 273: $13912-13917$

Laderoute KR, Alarcon RM, Brody MD, Calaoagan JM, Chen EY, Knapp AM, Yun Z, Denko NC, Giaccia AJ (2000) Opposing effects of hypoxia on expression of the angiogenic inhibitor thrombospondin 1 and the angiogenic inducer vascular endothelial growth factor. Clin Cancer Res 6: $2941-2950$

Livak KJ, Schmittgen TD (2001) Analysis of relative gene expression data using real-time quantitative PCR and the 2(-Delta Delta C(T)) Method. Methods 25: $402-408$

Luque A, Carpizo DR, Iruela-Arispe ML (2003) ADAMTS1/METH1 inhibits endothelial cell proliferation by direct binding and sequestration of VEGF165. J Biol Chem 278: 23656-23665
Matthews RT, Gary SC, Zerillo C, Pratta M, Solomon K, Arner EC, Hockfield S (2000) Brain-enriched hyaluronan binding (BEHAB)/ brevican cleavage in a glioma cell line is mediated by a disintegrin and metalloproteinase with thrombospondin motifs (ADAMTS) family member. J Biol Chem 275: 22695-22703

Munaut C, Noel A, Hougrand O, Foidart JM, Boniver J, Deprez M (2003) Vascular endothelial growth factor expression correlates with matrix metalloproteinases MT1-MMP, MMP-2 and MMP-9 in human glioblastomas. Int J Cancer 106: $848-855$

Naganuma H, Satoh E, Kawataki T, Amagasaki K, Satoh H, Nukui H (2003) Cell density regulates thrombospondin-1 production in malignant glioma cells. J Neurooncol 63: $147-153$

Nakada M, Miyamori H, Kita D, Takahashi T, Yamashita J, Sato H, Miura R, Yamaguchi Y, Okada Y (2005) Human glioblastomas overexpress ADAMTS-5 that degrades brevican. Acta Neuropathol (Berlin) 110(3): $239-246$

Plate KH, Breier G, Weich HA, Risau W (1992) Vascular endothelial growth factor is a potential tumour angiogenesis factor in human gliomas in vivo. Nature 359: $845-848$

Poon RT, Chung KK, Cheung ST, Lau CP, Tong SW, Leung KL, Yu WC, Tuszynski GP, Fan ST (2004) Clinical significance of thrombospondin 1 expression in hepatocellular carcinoma. Clin Cancer Res 10: 4150-4157

Porter S, Clark IM, Kevorkian L, Edwards DR (2005) The ADAMTS metalloproteinases. Biochem J 386: 15-27

Porter S, Scott SD, Sassoon EM, Williams MR, Jones JL, Girling AC, Ball RY, Edwards DR (2004) Dysregulated expression of adamalysin-thrombospondin genes in human breast carcinoma. Clin Cancer Res 10: 2429-2440

Rodriguez-Manzaneque JC, Milchanowski AB, Dufour EK, Leduc R, IruelaArispe ML (2000) Characterization of METH-1/ADAMTS1 processing reveals two distinct active forms. J Biol Chem 275: 33471-33479

Rossi MR, Gaile D, Laduca J, Matsui SI, Conroy J, McQuaid D, Chervinsky D, Eddy R, Chen HS, Barnett GH, Nowak NJ, Cowell JK (2005) Identification of consistent novel submegabase deletions in low-grade oligodendrogliomas using array-based comparative genomic hybridization. Genes Chromosomes Cancer 44(1): 85-96

Shweiki D, Itin A, Soffer D, Keshet E (1992) Vascular endothelial growth factor induced by hypoxia may mediate hypoxia-initiated angiogenesis. Nature 359: $843-845$

Tenan M, Fulci G, Albertoni M, Diserens AC, Hamou MF, El Atifi-Borel M, Feige JJ, Pepper MS, Van Meir EG (2000) Thrombospondin-1 is downregulated by anoxia and suppresses tumorigenicity of human glioblastoma cells. J Exp Med 191: 1789-1798

Tortorella M, Pratta M, Liu RQ, Abbaszade I, Ross H, Burn T, Arner E (2000) The thrombospondin motif of aggrecanase-1 (ADAMTS-4) is critical for aggrecan substrate recognition and cleavage. J Biol Chem 275: $25791-25797$

Vazquez F, Hastings G, Ortega MA, Lane TF, Oikemus S, Lombardo M, Iruela-Arispe ML (1999) METH-1, a human ortholog of ADAMTS-1, and METH-2 are members of a new family of proteins with angio-inhibitory activity. J Biol Chem 274: 23349-23357

Wang P, Tortorella M, England K, Malfait AM, Thomas G, Arner EC, Pei D (2004) Proprotein convertase furin interacts with and cleaves proADAMTS4 (Aggrecanase-1) in the trans-Golgi network. J Biol Chem 279: $15434-15440$

Zheng X, Chung D, Takayama TK, Majerus EM, Sadler JE, Fujikawa K (2001) Structure of von Willebrand factor-cleaving protease (ADAMTS13), a metalloprotease involved in thrombotic thrombocytopenic purpura. J Biol Chem 276: 41059-41063 